\title{
Implementasi Algoritma Apriori Untuk Menentukan Cross Selling Produk Pada Apotek RSUD Tugurejo Semarang
}

\author{
Implementation of Apriori Algorithm to Determine Cross Selling Product in the \\ Pharmacy of RSUD Tugurejo Semarang
}

\author{
Anggakara Ardiansyah ${ }^{1}$, Acun Kardianawati ${ }^{2}$ \\ Fakultas Ilmu Komputer, Universitas Dian Nuswantoro Semarang \\ e-mail: 1anggakaraardiansyah94@gmail.com , 2acun.kardianawati@dsn.dinus.ac.id
}

\begin{abstract}
Abstrak
Apotek Rumah Sakit Umum Daerah (RSUD) Tugurejo Semarang merupakan salah satu organisasi penyedia pelayanan masyarakat dalam bidang kesehatan khususnya sebagai penyedia obat dan alat-alat kesehatan (alkes) yang dibutuhkan pasien. Persediaan obat dan alkes pada Apotek RSUD Tugurejo Semarang penting untuk diperhatikan, karena mengalami penumpukan antrian dalam proses penjualannya, hal ini diisebabkan setiap menangani transaksi penjualan petugas masih harus mencari daftar obat satu persatu, sementara transaksi penjualan obat pe hari berkisar antara 1.000 hingga 5.000 transaksi. Data transaksi penjualan obat yang banyak tersimpan dalam suatu basis data sebenarnya dapat menghasilkan suatu pengetahuan baru bila melalui proses data mining. Salah satu teknik data mining adalah Association Rule dengan memanfaatkan cross selling produk melalui perhitungan algoritma Apriori. Algoritma Apriori digunakan untuk membantu menemukan sejumlah aturan asosiasi dari basis data. Dengan menerapkan algoritma apriori dengan acuan nilai minimum support $11 \%$ dan nilai minimum confidence $60 \%$ ditemukan pola transaksi pembelian obat berfrekuensi tinggi sebanyak 3 itemset yaitu Jika membeli abilify discmelt 10mg (aripiprazole) box 10 tab dan cath. Folley 2 way 16 (rusch/urocare) maka membeli apialasit drop dengan nilai support 18.6\% dan nilai confidence 96.87\% dan Jika membeli alprazolam 0.5 mg tab dan clonidin 0.15mg maka membeli nevirapine 200mg @60 (D) dengan nilai support $11.6 \%$ dan nilai confidence $90.62 \%$.
\end{abstract}

Kata kunci : Data Mining, Algoritma Apriori, Item set, Assotiation Rules, Cross-selling

\begin{abstract}
The pharmacy of the Regional General Hospital (RSUD) Tugurejo Semarang is one of the community service providers in the health sector, especially as a provider of medicines and medical devices (medical devices) needed by patients. Drug supplies and medical equipment at the Tugurejo Regional Hospital Semarang Pharmacy are important to note, because there is a queue accumulation in the sales process, this is because each sales transaction officer still has to find a list of drugs one by one, while day drug sales transactions range from 1,000 to 5,000 transactions. Many drug sales transaction data stored in a database can actually produce new knowledge through the data mining process. One of the data mining techniques is the Association Rule by utilizing cross selling products through the calculation of the Apriori algorithm. The Apriori algorithm is used to help find a number of association rules from the database. By applying a priori algorithm with a minimum reference value of $11 \%$ support and a minimum confidence value of $60 \%$ found a pattern of high frequency drug purchase transactions of 3 itemset namely if you buy abilify discmelt 10mg (aripiprazole) box 10 tab and cath. Folley 2 way 16 (rusch / urocare) then buy apialasit drop with a support value of $18.6 \%$ and a value of confidence of $96.87 \%$ and if you buy alprazolam $0.5 \mathrm{mg}$ tab and clonidin $0.15 \mathrm{mg}$ then buy nevirapine 200mg @ 60 (D) with a value of $11.6 \%$ and value confidence $90.62 \%$.
\end{abstract}

Keywords : Data Mining, Priori Algorithm, Item set, Assotiation Rules, Cross-selling.

Journal of Information System Vol. 4, No. 1, Mei 2019, hlm. 110-118

p-ISSN : 2528-0228

e-ISSN : 2528-0236 


\section{PENDAHULUAN}

Dengan semakin majunya teknologi dari waktu ke waktu pemanfaatan teknologi yang mudah dan praktis ini tidak dapat dipungkiri lagi bahwa proses bisnis sangat memerlukan adanya teknologi informasi yang menjadikan sebuah sistem informasi sebagai kebutuhan primer guna menunjang pengembangan sebuah sistem yang telah ada. Dengan sangat besarnya data yang dimiliki dapat berakibat pada proses penyampaian informasi. Agar didapatkan informasi yang berkualitas, sekumpulan data tersebut harus diproses sehingga menghasilkan informasi yang bermanfaat bagi semua pihak yang menerima informasi tersebut. Apotek RSUD Tugurejo Semarang adalah salah satu organisasi bisnis di bidang kesehatan yang menyediakan obat-obatan dan alat-alat kesehatan.

Apotek RSUD Tugurejo Semarang sudah menggunakan fasilitas teknologi komputer sebagai sarana teknologi informasi penginputan data, pemrosesan data, hingga mencetak hasil dari pengolahan data berupa informasi yang diinginkan. Dikarenakan apotek ini bertempat di sarana kesehatan umum, tidak dapat dipungkiri jika transaksi keluar masuknya obat sangat tinggi dan menghasilkan banyaknya data transaksi yang tersimpan tiap harinya dan menyebabkan proses transaksi penjualan obat memerlukan waktu yang lama karena masih menggunakan cara yang sudah terkomputerisasi tetapi masih menggunakan cara dengan memilih daftar obat atau menentukan kode obat satu persatu berdasarkan obat yang akan dipesan.

Berdasarkan Penelitian yang telah dilakukan, telah dilaksanakan pencatatan waktu proses transaksi sebanyak 10 transaksi penjualan obat pada apotek tersebut dan ditemukan $29.96 \%$ atau 31 menit waktu dari total waktu proses keseluruhan yaitu 135 menit dalam proses penjualan obat. Dapat dibayangkan jika waktu tersebut dapat dipersingkat agar tidak menimbulkan jumlah antrean yang begitu panjang. Untuk mempercepat proses penjualan tersebut dapat dilakukan dengan menggunakan ilmu Assotiation rules dan penggunaan algoritma apriori untuk menentukan item barang atau obat agar proses penjualan lebih mudah dan lebih cepat sehingga dapat mempercepat proses tiap transaksi yang akan mengakibatkan berkurangnya panjang antrean para pembeli obat.

\section{METODE PENELITIAN}

Pada penelitian ini mengambil objek pada Apotek RSUD Tugurejo Semarang, dengan jumlah data 500 transaksi penjualan

\subsection{Data Mining}

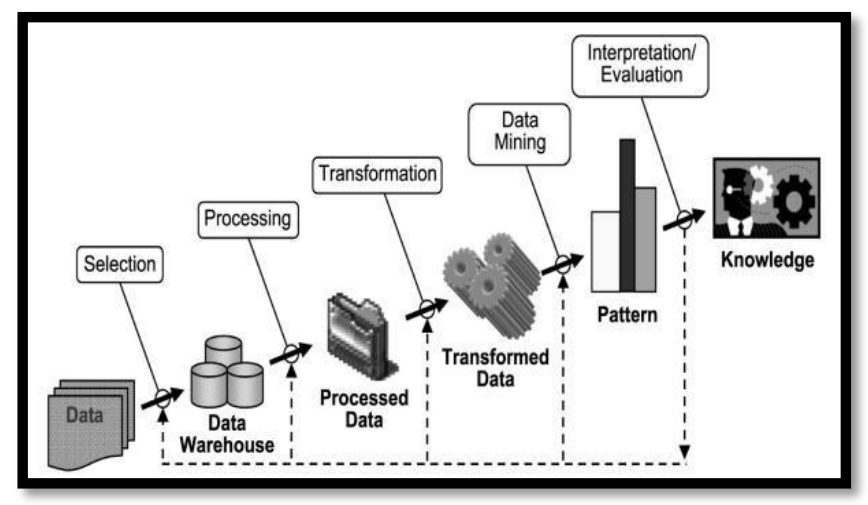

Gambar 1. Tahapan proses KDD ${ }^{[1]}$

Tahapan penelitian menggunakan proses knowledge discovery in databases (KDD) adalah sebagai berikut: 
1. Pengumpulan data, Sumber data utama yang digunakan dalam penelitian tugas akhir ini adalah data yang berasal dari data transaksi 1 bulan pada Apotek RSUD.Tugurejo Semarang.

2. Penyeleksian Data, yaitu melakukan proses pemilihan data yang tidak terpakai dan dibuang agar mendapatkan hasil yang sesuai. Dengan cara melakukan proses eliminasi data transaksi yang tidak memenuhi syarat minimum support barulah akan diketahui itemset. Proses pencarian itemset menggunakan bantuan aplikasi WEKA 3.8 Dengan berdasarkan tabel transaksi yang isinya 500 transaksi.

3. Preprocessing / Cleaning Tujuan dari proses pembersihan atau cleaning adalah untuk memilih atribut pada data transaksi penjualan yang akan menjadi fokus penelitian yaitu atribut nomor transaksi penjualan dan nama barang yang dibeli dan kemudian menghapus atribut yang tidak digunakan.

4. Transformasi data dalam data mining perlu dilakukan karena dalam proses data mining yang terkomputerisasi diperlukan bentuk data yang bisa diintegrasikan dengan aplikasi/tools yang digunakan.

5. Data Mining, penerapan data mining yang dipilih yaitu menggunakan metode asosiasi dengan memanfaatkan algoritma apriori karena dengan menggabungkan antara data mining dengan algoritma apriori untuk menghasilkan sebuah informasi baru berupa itemset obat yang didapatkan dari menghitung presentasi kebiasaan konsumen dalam membeli obat dari jumlah keseluruhan proses transaksi yang sudah dilakukan.

6. Evaluasi pola-pola yang telah diidentifikasi kemudian diterjemahkan atau disajikan kedalam bentuk yang dapat dimengerti untuk membantu pengambilan keputusan strategi bisnis.

\subsection{Aturan Asosiasi atau Assosiation rules}

Assosiation rules merupakan salah satu teknik didalam data mining untuk menentukan hubungan antar item dalam suatu dataset (sekumpulan data) yang telah ditentukan. Aturan asosiasi adalah bentuk jika "kejadian sebelumnya" kemudian "konsekuensinya". (If antecedent, then consequent), yang diikuti dengan perhitungan aturan support dan confidence. Suatu pola menggambarkan isi dari database yang belum diketahui dan mungkin tidak bisa diungkapkan secara langsung. Aturan asosiasi ditentukan oleh dua parameter [2], yaitu:

a. Support : Suatu ukuran atau nilai penunjang yang menunjukkan seberapa besar tingkat presentase kombinasi item dari keseluruhan transaksi.

b. Confidence : Suatu ukuran atau nilai kepastian yang menunjukkan kuatnya hubungan antar item dalam aturan asosiatif.

Kedua parameter diatas digunakan untuk menentukan kekuatan suatu pola dan menemukan pola yang memenuhi syarat minimum untuk support (minsup) dan syarat minimum untuk confidence (minconf).

\subsection{Cross Selling}

Cross Selling dapat dikatakan sebagai strategi bisnis yang paling sering digunakan dalam kegiatan marketing atau berjualan. Cross Selling merupakan suatu cara menjual produk atau jasa tertentu, kemudian menawarkan produk lainnya yang berbeda yang dapat dipasangkan penggunaanya kepada konsumen.[4]. Sebagai contoh dalam penggunaan jasa ojek dan taksi online. Pada saat menggunakan jasa tersebut, driver atau pengemudi ojek atau taksi tersebut menawarkan kepada penumpang untuk mengisi saldo yang dapat digunakan untuk pembayaran saat menggunakan jasa layanan tersebut.

\subsection{Algoritma Apriori}

Salah satu cara penghitungan yang sudah sering digunakan sebagai cara untuk menemukan sebuah pola berfrekuensi tinggi atau kebiasaan dengan informasi atau data yang sangat banyak atau besar. Yang dimaksud dengan pola berfrekuensi tinggi yaitu suatu kumpulan 
dari beberapa pola item didalam suatu database yang mempunyai tingkat atau support diatas batas dari pada lainnya yang sering disebut juga dengan istilah minimum support [3].

Agar dapat mengetahui apakah item itu dapat dikatakan sebagai itemset, data barang pertama harus dicocokkan dengan data barang selanjutnya seberapa besar barang tersebut keluar bersamaan. Dengan demikian perlunya digunakan rumus minimal support pada persamaan 1 dan 2 sebagai berikut:[3]

Support $(A, B)=P(A \cap B)$

Ssupport $(A, B)=\frac{\sum \text { Transaksi mengandung } A \text { dan } B}{\sum \text { Total Transaksi }}$

Setelah menemukan minimum support, hal yang perlu dilakukan selanjutnya adalah menentukan confidence dari itemset tersebut yang nantinya guna menggabungkan kedua item atau lebih dalam sebuah perhitungan Algoritma Apriori. Nilai confidence hanya dapat ditemukan jika pola frekuensi item ditemukan.Pada persamaan 3 merupakan cara untuk menghitung nilai dari confidence:[5]

Confidence $=\mathrm{P}\left(\mathrm{B} \mid \mathrm{A}=\frac{\sum \text { Transaksi mengandung } \mathrm{A} \text { dan } B}{2 ! \text { Transaksi Mengandung } \mathrm{A}}\right.$

Penggunaan penghitungan algoritma apriori pada prosesnya terdiri dari beberapa fase yang biasa juga disebut dengan iterasi. Dari tiap proses masing-masing iterasi dihasilkan pola dengan frekuensi item yang tinggi dan berjumlah sama banyaknya, dimulai dari tahap pertama yang terdiri atas pola berfrekuensi tinggi dengan banyaknya jumlah pasangan satu. Nilai dari fase yang pertama ini ditentukan dari menghitung serta menganalisa database.

\section{HASIL DAN PEMBAHASAN}

\subsection{Menghitung Nilai Support}

Untuk mencari sebuah kombinasi itemset dapat ditemukan dengan cara menggunakan rumus nilai minimum support, dengan data penjualan sebanyak 500 transaksi, maka langkah selanjutnya adalah menemukan golongan itemset-1 dengan cara melakukan proses eliminasi data transaksi yang tidak memenuhi syarat minimum support barulah akan diketahui kelompok golongan itemset-1. Proses pencarian itemset-1 menggunakan bantuan aplikasi WEKA 3.8 dan didapatkan hasil pada tabel 1.

Tabel 1. itemset-1

\begin{tabular}{cccc}
\hline Kode Obat & $\begin{array}{c}\text { Jumlah } \\
\text { Transaksi }\end{array}$ & $\begin{array}{c}\text { Total } \\
\text { Transaksi }\end{array}$ & Nilai Support \\
\hline A & 105 & 500 & $21 \%$ \\
B & 100 & 500 & $20 \%$ \\
C & 28 & 500 & $5.6 \%$ \\
D & 26 & 500 & $5.2 \%$ \\
E & 45 & 500 & $9 \%$ \\
F & 46 & 500 & $9.2 \%$ \\
G & 21 & 500 & $4.2 \%$ \\
H & 32 & 500 & $6.4 \%$ \\
I & 25 & 500 & $5 \%$ \\
J & 24 & 500 & $4.8 \%$ \\
K & 31 & 500 & $6.2 \%$ \\
L & 119 & 500 & $23.8 \%$ \\
M & 28 & 500 & $5.6 \%$ \\
N & 34 & 500 & $6.8 \%$ \\
O & 32 & 500 & $6.4 \%$ \\
P & 48 & 500 & $9.6 \%$ \\
\hline
\end{tabular}




\begin{tabular}{|c|c|c|c|}
\hline Kode Obat & $\begin{array}{c}\text { Jumlah } \\
\text { Transaksi }\end{array}$ & $\begin{array}{c}\text { Total } \\
\text { Transaksi }\end{array}$ & Nilai Support \\
\hline $\mathrm{Q}$ & 38 & 500 & $7.6 \%$ \\
\hline $\mathrm{R}$ & 59 & 500 & $11.8 \%$ \\
\hline $\mathrm{S}$ & 20 & 500 & $4 \%$ \\
\hline $\mathrm{T}$ & 55 & 500 & $11 \%$ \\
\hline $\mathrm{U}$ & 29 & 500 & $5.8 \%$ \\
\hline $\mathrm{V}$ & 26 & 500 & $5.2 \%$ \\
\hline W & 42 & 500 & $8.4 \%$ \\
\hline X & 38 & 500 & $7.6 \%$ \\
\hline Y & 30 & 500 & $6 \%$ \\
\hline Z & 62 & 500 & $12.4 \%$ \\
\hline AA & 65 & 500 & $13 \%$ \\
\hline $\mathrm{AB}$ & 31 & 500 & $6.2 \%$ \\
\hline $\mathrm{AC}$ & 51 & 500 & $10.2 \%$ \\
\hline $\mathrm{AD}$ & 22 & 500 & $4.4 \%$ \\
\hline $\mathrm{AE}$ & 17 & 500 & $3.4 \%$ \\
\hline $\mathrm{AF}$ & 119 & 500 & $23.8 \%$ \\
\hline AG & 21 & 500 & 4.2 \\
\hline $\mathrm{AH}$ & 31 & 500 & $6.2 \%$ \\
\hline AI & 36 & 500 & $7.2 \%$ \\
\hline AJ & 30 & 500 & $6 \%$ \\
\hline AK & 24 & 500 & $4.8 \%$ \\
\hline $\mathrm{AL}$ & 25 & 500 & $5 \%$ \\
\hline $\mathrm{AM}$ & 88 & 500 & $17.6 \%$ \\
\hline AN & 23 & 500 & $4.6 \%$ \\
\hline $\mathrm{AO}$ & 29 & 500 & $5.8 \%$ \\
\hline AP & 20 & 500 & $4 \%$ \\
\hline AQ & 59 & 500 & $11.8 \%$ \\
\hline AR & 21 & 500 & $4.2 \%$ \\
\hline AS & 31 & 500 & $6.2 \%$ \\
\hline AT & 28 & 500 & $5.6 \%$ \\
\hline $\mathrm{AU}$ & 16 & 500 & $3.2 \%$ \\
\hline $\mathrm{AV}$ & 13 & 500 & $2.6 \%$ \\
\hline AW & 30 & 500 & $6 \%$ \\
\hline $\mathrm{AX}$ & 32 & 500 & $6.4 \%$ \\
\hline AY & 55 & 500 & $11 \%$ \\
\hline $\mathrm{AZ}$ & 31 & 500 & $6.2 \%$ \\
\hline BA & 92 & 500 & $18.4 \%$ \\
\hline BB & 34 & 500 & $6.8 \%$ \\
\hline BC & 19 & 500 & $3.8 \%$ \\
\hline BD & 22 & 500 & $4.4 \%$ \\
\hline $\mathrm{BE}$ & 22 & 500 & $4.4 \%$ \\
\hline $\mathrm{BF}$ & 23 & 500 & $4.6 \%$ \\
\hline BG & 16 & 500 & $3.2 \%$ \\
\hline BH & 19 & 500 & $3.8 \%$ \\
\hline BI & 25 & 500 & $5 \%$ \\
\hline $\mathrm{BJ}$ & 26 & 500 & $5.2 \%$ \\
\hline BK & 26 & 500 & $5.2 \%$ \\
\hline
\end{tabular}

Setelah menemukan nilai minimum support dari tiap kode obat berdasarkan 500 data transaksi, penulis memutuskan untuk hanya mengambil nilai persentase minimum support yang diatas $15 \%$. Maka dari itu ditemukan 1-itemset yang memiliki pola berfrequensi tinggi terlihat pada tabel 2. 
Tabel 2. Hasil proses eliminasi nilai minimum support

\begin{tabular}{cccc}
\hline $\begin{array}{c}\text { Kode } \\
\text { Obat }\end{array}$ & $\begin{array}{c}\text { Jumlah } \\
\text { Transaksi }\end{array}$ & $\begin{array}{c}\text { Total } \\
\text { Transaksi }\end{array}$ & $\begin{array}{c}\text { Nilai } \\
\text { Support }\end{array}$ \\
\hline A & 105 & 500 & $21 \%$ \\
B & 100 & 500 & $20 \%$ \\
L & 119 & 500 & $23.8 \%$ \\
AF & 119 & 500 & $23.8 \%$ \\
AM & 88 & 500 & $17.6 \%$ \\
BA & 92 & 500 & $18.4 \%$ \\
\hline
\end{tabular}

\subsection{Menentukan kombinasi Itemset}

Setelah menentukan nilai minimum support dan mengeliminasi data yang tidak memenuhi syarat, maka langkah selanjutnya yaitu dengan mengkombinasikan k-itemset yang didapatkan sebelumnya agar didapatkan itemset- 2 .

Tabel 3. Hasil kombinasi 2-itemset

\begin{tabular}{cccc}
\hline KOMBINASI & COUNT & SUPPORT & CONFIDENCE \\
\hline A,AF & 93 & $18.6 \%$ & $78.50 \%$ \\
L,AF & 96 & $19.2 \%$ & $80.67 \%$ \\
A,L & 96 & $19.2 \%$ & $80.67 \%$ \\
B,AM & 60 & $12 \%$ & $60 \%$ \\
B,BA & 61 & $12.2 \%$ & $61 \%$ \\
AM,BA & 64 & $12.8 \%$ & $69.56 \%$ \\
\hline
\end{tabular}

Setelah menemukan 2-itemset yang tertuang pada tabel 3, langkah selanjutnya yaitu menemukan 3-itemset dengan cara yang sama yaitu melakukan proses kombinasi sama seperti saat mencari 2 -itemset sehingga diperoleh hanya 2 kombinasi pada tabel 4 .

Tabel 4. Hasil Kombinasi 3-itemset

\begin{tabular}{cc}
\hline KOMBINASI & COUNT \\
\hline A,AF,L & 93 \\
B,AM,BA & 58 \\
\hline
\end{tabular}

Proses membuat itemset dihentikan dikarenakan tidak ditemukannya kombinasi selanjutnya. Dengan begitu, maka dapat disimpulkan bahwa :

1. Jika seseorang membeli obat dengan kode A dan AF, maka kemungkinan besar orang tersebut juga akan membeli obat dengan kode $\mathrm{L}$.

2. Jika seseorang membeli obat dengan kode B dan AM, maka kemungkinan besar orang tersebut juga akan membeli obat dengan kode BA.

\subsection{Pembentukan Aturan Asosiasi}

Setelah pemrosesan data selesai hingga mendapatkan hasil nilai minimum support dan mendapatkan kombinasi itemset dengan memiliki pola frequensi tinggi, langkah selanjutnya yaitu dengan mencari aturan nilai minimum confidence berdasarkan data yang didapatkan pada tabel hasil kombinasi 3-itemset. 
Tabel 5. Hasil Aturan dengan Asosiasi

\begin{tabular}{lrr}
\hline \multicolumn{1}{c}{ ATURAN } & \multicolumn{1}{c}{ CONFIDENCE } \\
\hline $\begin{array}{l}\text { Jika membeli obat kode A dan AF, maka akan membeli obat dengan } \\
\text { kode L. }\end{array}$ & $93 / 96$ & $96.87 \%$ \\
$\begin{array}{l}\text { Jika membeli obat kode B dan AM, maka akan membeli obat dengan } \\
\text { kode BA. }\end{array}$ & $58 / 64$ & $90.62 \%$ \\
\hline
\end{tabular}

Tabel 5 merupakan tabel hasil analisa menggunakan data mining dengan memanfaatkan algoritma apriori untuk mengetahuai besarnya presentase atau kemungkinan kelompok item tersebut keluar secara bersamaan.

\subsection{Perbandingan Sistem}

Guna mengetahui apakah program penjualan yang sudah ditambahkan dengan item set lebih efektif dan efisien pada saat proses administrasi. Pada tabel 6 ini adalah hasil perbandingan langsung antara program penjualan obat yang sedang digunakan dengan program penjualan obat yang berisikan item set.

Tabel 6. Perbandingan proses waktu program lama dengan program baru

\begin{tabular}{|c|c|c|c|}
\hline \multirow{2}{*}{$\begin{array}{c}\text { Nomor } \\
\text { Transaksi }\end{array}$} & \multirow[t]{2}{*}{ Macam Obat } & \multicolumn{2}{|c|}{ Waktu Transaksi (hitungan detik) } \\
\hline & & Tanpa Item set & Drngan Item set \\
\hline 1 & $\begin{array}{l}\text { ABILIFY DISCMELT } 10 \mathrm{MG} \\
\text { (ARIPIPRAZOLE) BOX } 10 \mathrm{TAB} \\
\text { TABLET TAMBAH DARAH } \\
\text { APIALIST DROP } \\
\text { CLONIDIN } 015 \mathrm{MG}\end{array}$ & 85 & 36 \\
\hline 2 & $\begin{array}{l}\text { ALPRAZOLAM } 0,5 \text { MG TAB } \\
\text { CTM } 4 \text { MG } \\
\text { DIGOXIN 0.25 MG TAB } \\
\text { CLONIDIN O,15 MG }\end{array}$ & 67 & 29 \\
\hline 3 & $\begin{array}{l}\text { ABILIFY DISCMELT } 10 \mathrm{MG} \\
\text { (ARIPIPRAZOLE) BOX } 10 \mathrm{TAB} \\
\text { TABLET TAMBAH DARAH } \\
\text { APIALIST DROP } \\
\text { OXYGEN SENTRAL / LIQUID } \\
\text { (LT }\end{array}$ & 93 & 37 \\
\hline 4 & $\begin{array}{l}\text { ALPRAZOLAM 0,5 MG TAB } \\
\text { CLONIDIN 0,15 MG } \\
\text { NEVIRAPINE } 200 \mathrm{MG} @ 60 \text { (D) }\end{array}$ & 72 & 31 \\
\hline 5 & $\begin{array}{l}\text { ABILIFY DISCMELT } 10 \mathrm{MG} \\
\text { (ARIPIPRAZOLE) BOX } 10 \mathrm{TAB} \\
\text { APIALIST DROP } \\
\text { CATH FOLLEY } 2 \text { WAY } 16 \\
\text { (RUSCH/UROCARE) }\end{array}$ & 57 & 19 \\
\hline
\end{tabular}

Dari tabel 6 telihat bahwa perbandingan proses penjualan dengan itemset lebih cepat dibandingkan dengan tidak menggunakan itemset. Dimana pada transaksi 1 membutuhakn waktu 85 detik tanpa item set, sedangkan dengan item set hanya 36 detik saja. Begitupun sampai dengan transaksi 5 yang berdampak pada pengurangan panjangnya antrean para pembeli obat. 


\section{KESIMPULAN} berikut:

Dari tahapan yang sudah dilakukan maka dapat kesimpulan dari penelitian ini sebagai

1. Proses administrasi penjualan obat apotek RSUD Tugurejo dapat dipersingkat waktunya dengan memanfaatkan itemset dan aturan asosiasi didapatkan pengetahuan baru tentang obat yang biasanya dibeli oleh pasien berdasarkan seberapa sering kumpulan obat itu terjual secara bersamaan

2. Pada proses analisis data mining menggunakan algoritma apriori dengan acuan nilai minimum support $11 \%$ dan nilai minimum confidence $60 \%$ ditemukan pola transaksi pembelian obat berfrekuensi tinggi sebanyak 3 itemset.

- Frekuensi 2-itemset

- Jika membeli obat abilify discmelt 10mg (aripiprazole) box 10 tab maka membeli cath. Folley 2 way 16 (rusch/urocare) dengan nilai support $18.6 \%$ dan nilai confidence $78.15 \%$

- Jika membeli obat apialist drop maka membeli cath. Folley 2 way 16 (rusch/urocare) dengan nilai support $19.2 \%$ dan nilai confidence $80.67 \%$

- Jika membeli obat abilify discmelt 10mg (aripiprazole) box 10 tab maka membeli apialist drop dengan nilai support $19.2 \%$ dan nilai confidence $80.67 \%$

- Jika membeli obat alprazolam $0.5 \mathrm{mg}$ tab maka membeli clonidin $0.15 \mathrm{mg}$ dengan nilai support $12 \%$ dan nilai confidence $60 \%$

- Jika membeli obat alprazolam 0.5 mg tab maka membeli nevirapine 200mg @ 60 (D) dengan nilai support $12.2 \%$ dan nilai confidence $61 \%$

- Jika membeli obat clonidin $0.15 \mathrm{mg}$ maka membeli nevirapine 200mg @60 (D) dengan nilai support $12.8 \%$ dan nilai confidence $69.56 \%$

- Frekuensi 3-itemset

- Jika membeli abilify discmelt $10 \mathrm{mg}$ (aripiprazole) box 10 tab dan cath. Folley 2 way 16 (rusch/urocare) maka membeli apialasit drop dengan nilai support $18.6 \%$ dan nilai confidence $96.87 \%$

- Jika membeli alprazolam $0.5 \mathrm{mg}$ tab dan clonidin $0.15 \mathrm{mg}$ maka membeli nevirapine 200mg @60 (D) dengan nilai support 11.6\% dan nilai confidence $90.62 \%$

3. Berdasarkan perbandingan proses penjualan obat yang sudah memanfaatkan itemset dengan tanpa itemset dapat disimpulkan bahwa proses penjualan dengan itemset lebih cepat dibandingkan dengan tidak menggunakan itemset dapat akan berdampak pada pengurangan panjangnya antrean para pembeli obat.

\section{SARAN}

Hasil penelitian yang menerapkan metode association rule menggunakan algoritma apriori pada apotek RSUD Tuguejo ini, diharapkan dapat diimplementasikan sehingga akan mendapatkan hasil lebih maksimal dibandingkan menggunakan sistem manual dalam menangani transaksi penjualan obat sehari-hari.

\section{DAFTAR PUSTAKA}

[1] F. A. H., Data Mining, Yogyakarta: ANDI, 2013.

[2] M. Fauzy, K. . R. S. W dan I. Asror, "Penerapan metode association rule menggunakan algoritma apriori pada simulasi prediksi hujan wilayah kota bandung," Jurnal Ilmiah Teknologi Informasi Terapan, vol. 2, no. 3, pp. 221-227, 2016.

[3] Santoso, Pengenalan Algoritma Apriori dan Tujuannya, 2007. 
[4] S. L. Dewati, "Analisa pola transaksi obat menggunakan algoritma apriori," Universitas Dian Nuswantoro, Semarang, 2015.

[5] I. Wijhah, "Analisis Asosiasi Data dengan algoritma apriori untuk sistem pendukung keputusan penjualan barang berbasis web," Universitas islam negeri sunan kalijaga, yogyakarta, 2015. 